\section{SCATTERED NATURE: MIGUEL BAKUN}

\section{Artur Freitas}

ABSTRACT: The painter Miguel Bakun worked during the 1940's and 1950's and his paintings are little known in the Brazilian art historiography. Bakun's paintings can be interpreted as a way of questioning the dichotomy between "academic" and "modern" in Brazilian context. This questioning is interesting for an expanded understanding of Brazilian art in the first half of the 20th century.

KEYWORDS: Miguel Bakun, Brazilian art, Modernism

\section{THE BAKUN ISSUE}

Miguel Bakun is one of those painters we may call "pictorial". That's right, as redundant as it is: a pictorial painter. One of those who believes in the viscous handling of paint, in the loaded palette, in the fat stroke of the brush, which delays the eye and appeals to the touch. Not that there is no drawing in there; it's just that, for Bakun, the act of drawing, fundamentally clumsy, is almost always the result, not the cause of the act of painting. In his paintings, it isn't rare, for example, for the edges to the painted areas to be fluid, slippery - a little ill-behaved, I would say, towards the linear structure of the objects. For this reason, in most of his paintings, colors is not the filling colors, but a kind of matter imperative. From lawns to fences, from houses to trees and painted bushes, it's the plastering that literally builds the spaces and goes forth from one side to another, seeking to dilute frontiers of objects that now always fit its own margins. Pictorial matter, for Bakun, is by definition a subject in itself, but a deviated one, sometimes rude and clumsy, although always honest and unforeseen - anyhow, one of the many forms that the experience of modern painting took on in the contradictory context of Brazilian art.

As a descendant of Slavs and the son of a railwayman of little wealth, Miguel Bakun posesses poor art education. In one quick research, every newspaper article, catalogue text or headword will describe him in the same way: as a "self-taught painter". And truthfully, Bakun did not attend any art courses; he had to learn how to paint on his own, by looking at things, at his own paintings and others's, which is not in fact an issue. The most important question towards this point is not about being self-taught, but to be a provincial self-taught person, as he is. Born in 1909 in Marechal Mallet, countryside of Paraná, Brazil, Bakun began painting in Curitiba, in the beginning of the 30's, where he lived and worked up to the day he died, in 1963. In this period, and overall during the decades of 1940 and the 50's, when he was at his fullest, the circuit of art in Curitiba already existed, but was as fragile as a castle made of cards. The trade of works of art, for example, notwithstanding some rare private orders, restrains itself to what was seen and bought through the displays of the few stores in XV Street, downtown. The consecration of artists, a necessity flavored by domestic fights, is due to award-givings of two annual available events, the Salão Paranaense created in 1944 and the Salão da Primavera, in 1947. Art criticism, in its turn, demonstrates more good will than visual understanding, and in general is done by humanist and romantic attorneys - which must actually explain why the best texts on art at the time were written not by critics, but by artists themselves, as is the case of the Joaquim magazine, which went around between 1946 and 1948. And, in the end, as to the formal education in visual arts, it's worth reminding that 1948 was the year in which the state's public power inaugurated the Paraná School of Music and Visual and Performing Arts (Escola de música e belas artes do Paraná) - or Belas - which, until the 70 s, was the only option for a higher level of education for the artists living in that region. Almost forty years old and little keen to theoretical discussions, Bakun avoids the school environment of the Visual and Performing Arts - just where his colleagues Guido Viaro and Theodoro de Bona would be lecturing and where all future modern generations would be studying from the year of 1950 on. On the other hand, the events, these ephemeral and illusory oasis of celebration, would soon be a true obsession to the artist: from 1947 to 1962, Bakun would be in no less than 29 of these 32 local events, and awarded at them 16 times. Not that that means much. Doubtlessly, Bakun was relatively known, unless in the context of Curitiba: he took part in all events in Paraná he desired, got awarded in some of them, calls the critics's attention and has few but important local MECENAS, among which a state's governor. The problem, as I see it — the Bakun issue, as I like to call it —, was not necessarily of knowledge, but of understandment.

Bakun's painting, overall his scenery painting, with all that viscous and confuse paint, that UNPRECISE drawing and that flat spaciality, 
represents a fracture in the "understandment" of art that went around at the time. In general terms, we could say that Bakun's Curitiba, in the AFÃ of self-modernization, lets out the terms of the eternal conflict between "academics" and "moderns", in such a fashion that makes Bakun's painting able to be recognized, but not understood. Schematizing, Curitiba from the 40s to the 50 s, among a thousand changes, tends to counterpose two contrary forces: the legacy of the norwegian painter Alfredo Andersen in the academic side, and the strong presence of the italian painter Guido Viaro, in the "modern" side. Facing this polarization — which in some way demonstrates more general problems than brazilian painting Bakun's word always rises unfit, and it's inevitably misunderstood — which, by the way, is actually a virtue, if we can place the artist's work facing these two poles.

\section{“ACADEMICS” AND “MODERNS” IN BAKUN'S CURITIBA}

Starting off with the first pole, we need to perceive, right off, that it's not possible to literally interpret what was called, at the time, "academic". The term, basically pejorative, is IMPRECISE enough to label, without sugarcoating, each and every painting that based itself in the space limitations of the naturalist system. In the case of Curitiba, "academics" are, overall, the "pupils of Andersen", that is, a small but varied group of painters that had been through the Curitibean atelier of the norwegian master, and shared the falvors of an electic PAISAGISMO->SCENERY-MAKING with him, in a rather fin-de-siècle fashion. Deceased in 1935, Alfredo Andersen left in Curitiba a whole generation of pupils. These are artists like Freyesleben, Estanislau Traple, Lange de Morretes, João Ghelfi and, in parts, Theodoro De Bona - artists that, despite lack of national projection, were essential to the formation of a local circuit of art. Surely, these aren't artists in equality to each other; even so, it's possible to see masters and pupils among them, a common core of objectives and procedures.

For example, with Andersen, they all learnt something visible in their paintings — something that the old master called "the truth of nature". It regarded, then, supposing that it wasn't properly "nature", but "natural perception of things" the right guide for appreciation and judgement in the act of painting. Andersen loathed the usage of prints and photographs in his classes and demanded from his students the direct experience of looking, the exhaustive practice of drawing, together with the understanding of the linear perspective. In the "academics" context, therefore, what rules the limitations and overlapping of objects, the VOLUMETRIA of light- and-dark and the evoking of depth, in first place, are the logics of "naturalistic" drawing. On the other side — and here there is no contradiction - it's exactly the safety of drawing, allied to the romantic taste of sketching, that will make appear in these same artists the taste for the called "PAINTING OF STAINS - PINTURA DE MANCHAS". In these conditions, the brushstroke frees itself ma non troppo, for it expands itself to the limits of perceived nature. It's evidently not about impressionism, because there's nothing there that suggests the systematic analysis of light and perception. The free and visible brushstroke, in these paintings, is only a luminous and punctual effect: a general evokation of a plausible "atmosphere" at its best. As had already occurred in the case of the Grimm group, in Rio de Janeiro, the Andersenian PINTURA DE MANCHAS is interested with the flowing aspect of the brushstroke not when its destructible, but only when it highlights the spacial imperatives of "correct drawing".

In the end of the 40s, and overall in the 50s, the post-war politization and the internationalization of modernity conflicts end up putting in crisis the stable world of "academic" painting, even in Curitiba. The magazine Joaquim engages in an open campaign against the Andersen legacy and spreads throughout the city an officious modernism, well-anchored in icons such as Portinari and Di Cavalcanti. Bakun, in his turn, finds himself in the middle of a cross-fire and had some difficulty situating himself. Adopted by modernist forces, the artist has an exotic feature, kind of out of control, and his drawing couldn't be called "correct"; but he's stil a local scenery painter - a landscaper whose brushstrokes, misinterpreted as "MANCHAS", guarantee himself some renown even in the most conservative local events.

In the context of conflict between "academics" and "moderns", the italian Guido Viaro rises up as the synthesis-figure of the will of artistic renovation in Curitiba. It's, as has already been said, about our second pole of discussion. Just like Alfredo Andersen, Viaro was able to converge around himself, through teaching and his own work, a whole generation of younger artists. But unlike Andersen, the italian didn't have to "foundate" a means of art; his idea was to simply update it in regards to what was at the time taken to be "modern" - and certainly the legacy of Andersen didn't fit the plans, unless as a villain to be defeated. By the end of the 40s, with Viaro's and also Poty's participation in the Joaquim magazine, the kind of renovation that interests the next generations starts to get clearer. In opposition fo the victory of "natural perception", all of it anchored to the equilibrium between nature spaciality and perspective rationality, the new conception of painting ends up 
taking into consideration other devices of signification, such as the deformation of figures, the synthesis of visual information and the spacial compression of planes.

Anyway, it's also necessary to affirm that the "renewed" painting in Bakun's Curitiba, in the end, owes less to modern painting, understood in a wide sense, than to the modernist graphic arts properly speaking. It may sound a bit odd, but it we have in mind the importance of illustrations in the Joaquim magazine and overall the interest that the Engraving clubs would arise in Parana as they did, we will understand that the matrix of these transformations is more of a "graphic" order, say, than of a "pictorial" order per se. By the way, such privilege of drawing seems to be a characteristic not only of Paraná modernism, but of Brazilian modernism as a whole. In both cases, the passage of an "academic" visuality to a "modern" one occurs without the mediation of a "pictorial" experience of impressionism, which brings the artists to jump from a "graphic" conception to another. Unlike the European case, in Brazil, it's possible to go from Pedro Alexandrino to Di Cavalcanti — or from Andersen to Viario — without necessarily having to understand the journey of painters less adjusted to such dichotomy — which may perhaps explain something about the origins of the Bakun issue.

\section{THE DISPERSATION OF SCENERY: FIRST NOTES}

Miguel Bakun's painting suffers from a chronic issue of evaluation: even if it is the work of a modern painter and great landscaper, such paintings were little studied as languages and even less as landscapes. Such disproportion between work and judgement, in my understanding, owes itself to the dissemination, in the field of art, of that what I call the anectode seduction, that is, the seduction for that order of "explanations" whose arguments are based in the author's biographical strange facts than in the specificities of his work. Well, the fact is that the case of the artist, under this perspective, becomes really an exemplary case. Living, Miguel Bakun was a much weird character, tormented, religious, full of manias, with a biography filled with anecdotes. Dead, Bakun is stalked, victimized, a misundestood genius, a martyr that refuses the system's stupidity and in the end hangs himself with a rope, in the back of his own house. For these and for others, as it's well-known, the artist was nicknamed "Paranả's Van Gogh" — what ended up becoming, with respect towards his work, one more slope in the road than an appropriated key to reading.

In this way, I say from the beginning that I intend, in the next pages, to approach Bakun's scenery painting without, however, recurr to the theme of suicide or any of his life's neverending oddities. In the same way - and I hope to be forgiven by the reader —, I say that I will not approach in this text his few but comprehensively known animist paintings. Much to the contrary: here, my idea is to actually help to interpret a side of Bakun yet little explored. From 1946 to mid-50s, approximately, Miguel Bakun ellaborates and deepens those who would become the main elements of his work. This, we can say, is the moment of his poetic construction. From then on, it begins to become obvious that Bakun's trajectory doesn't present a linear development, because it's made more of comings and goings than of successive advances. Awarded in almost every local event since the end of the 40s, the artist's works follow a curious itinerary: the're moderately accepted between "academics" and "moderns" — for they allow thin approaches to both sides — but basically different from both, overall in its way of structurizing space and conceiving matter. Replacing the logic of the naturalist system or the disfigurations of modernist drawing, Miguel Bakun's painting ends up divided between a dispersive treatment and a liquefied brushstrok.e In this way, facing a context that has everything to think overall of the paper in the drawing of painting, his "pictorial" painting has always been a mystery to unfold. Already in 1946 and 47 , for example, it is justly through drawing, or better, through its difficulty or lacking, that criticism approached his rough and fleshy paintings: Nelson Luz talks of a "staggering drawing"; Osvaldo Nascimento says that the drawing is "faced in a secondary plane"; while Armando Ribeiro Pinto notes the "absence of architectural structure" in such painting. They're all right; but at that point, only Guido Viaro was able to notice a lacking in virtue. Bakun's paintings, according to Viaro, suggest a "lacking of drawing that resembles more a coat of arms than a real lacking"; in those paintings, he concludes, there's an elimination of "air in the sceneries as if it was a physics experiment". And it's true: in Bakun's work, "to eliminate the air" — that is, to make difficult the atmospheric evoking of a deep and naturalistic space - happens precisely because of the "lack of drawing", of the handling of pictorial matter, and not in the linear deformation of planes and outlines, something typical of the "modernist" key.

Particularly keen on this aspect is the case of a small scenery by Bakun, painted on card paper and dated as of 4th of July of 1946 (fig. I). In it, some of the main poetic makeshifts of the artist are already present. Painted over a precarious support, the painting, which represents an isolated house in the middle of the scenery, presents an expeditious treatment that contrasts with the small dimensions of the card. Although it's signed and dated, the painting 
resembles something like a practice - one of those quick and incomplete "sketches" to which tradition would reccomend better widening on a bigger and definitive support. However, for Bakun, being incomplete is in itself a complete source of signification. The artist, who always thinks figuratively, seems to trust in the observer's ability of visual reading, since that, in general, allows him to have a more active role in the interpretation of the imagery of his work. It's not rare, in this sense, that the descriptive clarity end up in conflict with a kind of feature that I would like to call "ostensible", for it's actually willing to "show off" the vestiges of its own doings. In this painting dated of 1946, for example, the horizon, which is relatively high, ends up dividing the scenery in two distinct patterns of showcasing features. The first, more timid, and situated in the superior third ofthe composition, consists in a whitened blue area that is more of a form of covering the support than properly a way of evoking, for example, the celestial infinity. There, the brushstrokes, visible and stretched over themselves, don't connect by the injunctions of a visual effect: they are born by necessity of covering, as if that blue and white net wasn't really necessary for the apperance of a "sky" in the painting. On another hand, below the horizon, the process is inverted: in regards to the support, it's not about chosing between covering it up or leaving it to show anymore; what's interesting in the painting of that vegetation is justly the disturbed and vibrating interaction, in this case, between paint and card. In these circumstances, in a terrestrial plane, Bakun counterposes the placidity of a sky that is brushed by paint to an electric and ruidous nature that builds itself in the alternancy between covering and showing, giving origin to a conflict of contraries in which the background, thus, becomes both color and image. Between contorted spreadings of blue, green and white paints, the raw hazelnut color of the card escapes in intervals of paint and invades the scenery, reassuring the flowing of objects represented there. In the thrill of the relations between mass and emptiness, the drawing dissipates in gesture, and there is no visual limitation that convinces us of the limits of things - that convinces us, for example, that a tree or a bush ends here or begins there.

Therefore, that's how the artist offers us, in one painting only, two forms of showcasing the feature: on one side, by concealment, as in a covering sky, which in this case is less a vision of the infinite than a way of covering with paint a piece of support; and in another side, by means of dispersion, as is the case of disturbed vegetation in the scenery, that here corresponds to the vibrating effect that results from nervous, incomplete procedures, and for that reason are permeable to the showcasing apparition of the support.
Still under this "dispersive effect" of scenery, another important painting is Entrada do tanque de Bacacheri (The entering of the Bacacheri tank), also from the 40s (fig. 2). It's a small oil on canvas in which the artist represented the surroundings of the Bacacheri neighbourhood's lake, in Curitiba, an old leisure spot in the city. In this work, it's the lake's surface, not the vegetation anymore, that predominates in the painting. The horizon, the superior limit located right above a narrow strip of grass, is higher than in the previous painting and leaves an even smaller portion of space for the sky. Although it's a leisure spot, the scenery is emptied of human traces: there are no constructions or characters, apart from three small ambiguous touches of dark paint - people or bushes? — that call attention to the centre and further down the lawn, next to a bigger bush. As an axis to the painting, nature interests Bakun as much as the showoff act of painting it.

In this work, the movement of paint now takes over a less rebellious and dramatic character. On another hand, the brushstrokes and spreadings's sense is still very visible and bases itself in a subtle game of oppositions. The author counterposes the horizontal touches of water and sky, which are predominant in the painting, to a series of opposed movements: vertical traces in three green ravines to the left; diagonal spreadings in the yellowed field to the background, and convulse and impredictable movements in two dark blocs of trees to the right and to the left. Even so, it's not only the articulated and internal game of paint that gives to the painting its flickering air. Lught, in this work, was not poured down the objects as usual: is simply came off from inside them — from within the boles and branches, lawns and clouds, from the reflexes on the lake. Again, it is the alternancy between paint and support that evokes such vibrating character of painting, with the exception being the luminous vibration, diffused all around, irradiated from within, from the bottom, from behind things, that is: comes from the canvas's blank. In a way, it's like the diffuse effect in this painting was a part of a downtempo labor of sight - as if the constant absence of paint didn't amount to more than a pretext for a deviated perception of boles, branches and clouds, or even of reflexes, passages, outlines. Distant from the naturalist atmosphere, Entrada do tanque do Bacacheri seems to come from a parallel worl, made out of the mixture of luminous sparks and grimes.

\section{DEVIATED NATURE}

In the realm of scenery, the evident devotion of Bakun towards nature is closer to the dimension of humble love than properly 
to those of drama or tragedy. In the only known testimonial by the artist, a manuscript of May 1960 which lies in the Museum of Contemporary Art of Paraná, Bakun assures that his conception of painting "was not in the drawing, forms, or colors". The artist explains: in a certain moment, "I began looking for God and I observed that He was in the flowers, the fruits and the colors. Life, light and movement are qualities that I revive in my paintings". Considered thus in a delicately affectionate and religious register, the artist's posture seems to be different, for example, from the exemplary postures of the romantic key. For him, the intense emotions of the natural world don't depend on the grandiloquent expression of wide, sublime and eventually awe-inspiring sceneries by analogy. Nature's beauty isn't in its monumental character, but, much to the contrary, in its most absolute simplicity. Of a widely known timid temper, Bakun incorporated the shyness and introversion of his own field of art, in order to potentialize it as a virtue. A rough abridgment would be to affirm that the more the artist's sceneries are unplugged from the debates between modernists and academics, the more they will find their own poetic dimension, so that before they get it right they have to get it wrong twice. Dislocated, therefore, from the perspective of a context that opposes naturalist drawing to the graphic solutions of modernism, Miguel Bakun ends up closing himself into a kind of liturgy of simplicity. In it, the natural beautiful, unending symptom of nature's good will towards men, needs to be saluted in some way, and the "pictorial" handling of a small scenery is still a symptom, precisely, of the good will of men towards nature. Contrary to the discussions about art, Bakun takes over an almost ingenuous empirism and goes around Curitiba, where he finds out the simplicity of invisible places, indefinite spaces, mere background yards or roadsides. In short, Bakun builds, with his sceneries, a simple iconography, in which the plasticity of forgotten nooks is as much a inconscient reaction towards the field of art as a form of affinity towards the bucolic context of Bakun's Curitiba. Painted in July 4th, 1947, Paisagem (Scenery) is a good example of this alliance between naturalist humbleness, pictorial paintings and simply iconography, overall if we take into consideration some procedures with which the artist encloses, in the painting, such relations (fig. 3). In it, Bakun sees nature as someone who wanders in the emptiness, looking down, absorbed, halfway concentrating between what he has in front of his eyes and what he has inside. Representing a lake with houses on its margins, Paisagem is one more Bakunian painting of high horizon, one of those that seem to compress the sky as if it were a needed supporting character to nature's leading disposition. In the superior portion of the painting, four houses, paired, divide an exiguous space, where they fit with accuracy, squeezed in a flattened rectangle that goes from the horizon's shaggy vegetation to the real limitations of the painting. At the houses's feet, a narrow strip of grayish-brown land, formed by viscous spreadings, goes through the painting from one side to another, dividing the composition in two unequal areas. From there downwards, all the painting's field is now dominated by the presence of the lake, with its ravines and reflexes.

The water, in this work, aside from providing the weight and measure of the canvas's visual field, is also a source of discrete perceptive instability. However, contrariwise to Entrada do tanque do Bacacheri, Paisagem doesn't affirm such instability through the alternancy between paint and background: even when it's visible, the canvas's web doesn't appear in a systematic way, and restrains itself to some points of the houses or the earth. The strategy, thus, is now different, and consists basically in exploring the plastic ambiguity of the water mirror. Utilizing a high horizon, Bakun takes advantage of the lake's extension and the flowing of reflexes in the inferior portion of the painting to recover, as an image, the flatenned or absent universe in the superior portion, as is the case of the sky, the houses and some trees. Such recovering, however, is never mere application of reflexive logics of images. Much to the contrary: it is as if that water's placidity wasn't servicing the contemplation, but the doubt. We see in the lake, for example, that three inverted Araucaria trees reappear as ghosts and dominate the composition, echoing in their crowns the horizontality of four ravines that emerge right about from the water. The Araucarias's trunks go forth up to two ravines, but curiously they don't proceed up them, as it would have been expected. Between both raivnes and solid ground, situated right above, the reflexes of trunks simply disappear, as if the aquatic images referred to total or partially invisible trees. By the way, in the world of reflexes, the smallest of the three Araucarias doesn't even have a trunk and seems to fluctuate above a parallel universe in which gravity doesn't exist and mirrors don't mirror.

A little to the right, also in the water, we can see the inverted images of a white house and a unknown tree. Contrariwise to the Araucarias, now it's possible to identify in the scenery the reflected objects, for we find in the terrestrial plane its correspondent houses and trees. On another hand, again, it's through the absence, not the presence, that Bakun mixes naturalist rationality. Like a playful mirror, the lake seems to be able to chose what it's going to reflect and what it won't. And indeed, only one of the four houses is reflected on it - even though, in a terrestrial environment, all of them are lined up and situated at the same distance from the gaze. $0 \mathrm{n}$ the 
water, the horizon's straightness, which at first should determine that everything in the scenery grows from the same ground, becomes unstable and disarranged. The tree on the right's reflection comes from a ravine different from the one from which comes the house's reflection. That aside, there's also all that pool situated between the ravines and solid ground, where the blue reflected from the sky occupies exactly the place of the ground's reflection, which should be there. Paisagem, in short, is a nice example of how Bakun's subtle iconography, made of simple excerpts from nature, doesn't stop the confluence of unstable senses, as is the case of ground that becomes sky in water or vice-versa.

\section{LIQUID AND WILD: BAKUNIAN FEATURES}

Simultaneously, in other works, the artist begins to make use of a feature we may call "liquid". In general, it's a form of covering support through straight, long, liquefied brushstrokes, generally used in the construction of objects that are also long, as trees, fences and boards. A clarifying example in this subject is Praça Tiradentes, a small oil on canvas painted by Bakun still in the 40's (fig. 4). Except from the yellowish foliage, almost everything that you see in this painting softens into a flowing, slippery trait. The contrasts, marked in other paintings, now weaken into translucent visuality. In between brushstrokes, the canvas reappears, punctuating shades of white that have roles of themselves. Once more, we're facing a feature that's showing itself off and therefore is up to showcasing its internal pictorial procedures, with the difference that now the dispersion of the scenery isn't in the spreading's vibration, as in Bakun's turbulent vegetations, but in the liquefied effect of the brushstrokes. It's not in vain that Praça Tiradentes is an urban scenery, a main spot in Curitiba where, in the place of parks and streams, predominate the buildings, concrete and asphalt.

In the city's scenery, the geometric edges of walls and cars are smoothed in the sinuous character of the brushstrokes. The drawing's limits are fluid and pleasantly smooth, as if a part of the humor had infiltrated in the scenery and forced the perspective to shake. The buildings seem to be made of jelly, what, in a good measure, ows itself to the brush's ostensible work. The building's big bluish wall to the right is an example: all the left side of this wall is made of a single, liquid and certain stroke, that begins in the beginning and ends at the end, where it has to, defying a smoothed, but curiously precise verticality - almost an exact science of the inexact. And we find the same in other spots in the painting, as in the high ocher building to the left, made of strokes that are equally liquefied, precise and vertical, or even in those four cars parked in the street, painted in one turn only.

Another important work that works with fluid strokes, although now they're seen as alternated areas of plastering and raw canvas, is Porta dos sonhos (Door to dreams), a small oil on canvas, probably painted in the beginning of the 50's (fig. 5). To a certain degree, this paintings doesn't only relate diverse former pictorial procedures: it makes of its own relation a poetic subject. In it, the artist works with a game of openings and closings, which, not by chance, correspond to distinct but complementary features. The look, in this work, resembles that of a spy or a voyeur: we see without being seen, from crevice to crevice, advancing into other's personal lives. In the field of imagery, we're protected behind a dense foliage, which covers, in the pictorial field and in a circular manner, all borders of the canvas, from high up to down low. Just ahead, through the vegetal disorder, we see the detail of a house. In the boarded walls, a very small portion of the house's interior escapes through the crevice of an indiscrete door that is ajar and soon we realize: we're snooping in.

Although, what we truly see is only a promise of a look. All intimacy of the house is shortened to a streak of minimal horizontal strokes. In counterposition, we also notice the decisive vertical presence of the boards on the door. As is the case of the buildings and cars in Praça Tiradentes, we're facing once again a certain geometry that is however unstable - liquidly organized. The difference now is the degree of precision. In Porta dos sonhos, the house door is made of an unusual material, in which act and thing are mixed up: each board is a gesture and in each gesture is a board - as a matter of fact, it's a situation that is taken to the extreme just ahead, where two almost magic strokes, straight as a ruler, cut the space and lean on the walls, under the form of two thin beams. On another hand, contrasting with this liquefied but civilized world, Bakun can't help himself and spills right around it all, in the savage world of vegetation, a huge load of leaves and flowers and limbs and twigs that are spinned into a barbarious feature. Once again, it's the relation between the plastering of paint and the uncovered background that shakes the dispersion of scenery. The shock between both features - the house's on one side and the vegetation that surrounds it in the other - seems to confirm the shock between two worlds: yes, nature wants to engulf human vestiges, and it's about to. As a result, the dispersive treatment of the plane comes into conflict with the look's voyeurism and tends to take over the canvas. Ostensible as a coated wall, the rough feature of nature spreads from the canvas's edges inwards and planes the painting. 
Although it wasn't anything systematic, such procedure of pictorial flattening of the visual field is noticeable in other paintings from the 50 s, as is the exemplary case of $\mathrm{Na}$ clareira (In the clearing), painted around the year of 1957 (fig. 6). In this work, all the painting's space is invaded by the unstable oscillating of nature. In a soft plongée, the horizon escapes by the air up high and makes us look down. The angle, actually, is a little odd: Bakun seems to have pulled the scenery by its leg, as if it were possible to knock the whole scene down, folding it over the painting's plane itself. The sky, already squeezed in other works, now doesn't even fit the canvas; what remains is only the continuous dispersion of a ground that is made of trees and foliage and lawn, all at the same time. As a strategist in combat, the artist doesn't paint a painting: he occupies all spaces, advancing with his turbulent plastering over each centimeter of the canvas. Almost in the center of it, a couple moves with difficulty, midway to sitting on the landscape and dissipate in the viscous plastering of paint. The narrative, lacking and vague, is nothing more than a pretext for the pictorial ravishments of painting. In a sense, as occurs in other similar paintings of Bakun's, Na Clareira synthetizes something important in the Bakun issue - something that, in my understanding, touches the ambiguous condition of being recognized without necessarily understood. In the end of the 50's, the field of art in Curitiba is divided in three poetic forces: in first place, a still naturalist figuration, called "academic"; coming in second, a "modernist" figuration, turned to the deconstruction of correct drawing; and, finally, an emergent abstraction of an informal edge, practiced in general by very young artists. Facing this scenery, Bakun keeps having trouble fitting in and follows a trajectory basically isolated and personal. In general terms, his intentions make him close to figurative modernists such as Paul Garfunkel, Alcy Xavier or Guido Viaro. In poetic terms, however, his keenness for nature, in one side, and the dispersion of the feature, in the other, make Bakun a fundamentally contradictory figure. A figure whose works, in the context of Curitiba, are close to all but are not mistaken by anything. It's curious, therefore, that an abstract treatment of the plane and forms come justly from a heartened approximation towards nature. The contradiction is clear: the ostensible patterns of paintings like $\mathrm{Na}$ Clareira end up getting close to informal abstraction; that same abstraction that, already in 1957, began to gain institutional spaces and soon dominated the events in Parana in 1961 and 62, punctuating the crisis of the Bakunian figuration. But a crisis not of, let's say, poetry, but of poetic understanding. In short, in the Curitiba of the 60 's, Bakun is already dead, even before he dies.

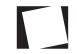

ARTUR FREITAS is a History of Art researcher. He acquired his phD and master's degree in History from the Universidade Federal do Paraná (PGHIS/UFPR), and undergraduated in Arts in the same institution (DEARTES/UFPR). He is also a professor in the Faculdade de Artes do Paraná in Universidade Estadual do Paraná (FAP/UNESPAR) and in the Post-graduation (master's and doctorate's) program in History in the same university he majored in the subject. Additionally, he's leader of the research group NAVIS - Núcleo de Artes Visuais (CNPq) and the author of Arte de guerrilha (Edusp, in press), Solar da gravura (Medusa, 20II) and Tony Camargo (Berlendis \& Vertecchia, 20II). 
